\title{
ADAPTIVE CONTROL OF A DENITRIFYING BIOFILTER WITH APPLICATION OF THE SUBSTRATE CONSUMPTION RATE
}

\author{
J. Czeczot ${ }^{10}$, M. Metzger ${ }^{1}$, J.P. Babary ${ }^{2}$ \\ ${ }^{1}$ Institute of Automatic Control, Technical University of Silesia \\ ul.Akademicka 16,44-100 Gliwice, Poland, jczeczot@ia.polsl.gliwice.pl \\ ${ }^{2}$ Laboratoire d'Analyse et d'Architecture des Systemes \\ Centre National de la Recherche Scientifique (LAAS/CNRS) \\ 7, avenue du Colonel Roche, 31077 Toulouse Cedex 4, France, babary@laas.fr
}

\begin{abstract}
This paper deals with the generalised approach to the adaptive control of a denitrifying biofilter with application of the substrate consumption rate. It is shown how to derive the control law on the basis of the simplified form of the dynamical equation written for the controlled variable with the possibly minimal knowledge about the process kinetics and components. In this equation all reaction rates are replaced by the only one time varying parameter (substrate consumption rate) and its value is estimated on-line by the recursive least-squares method at the biofilter outlet to ensure the adaptability of the control law. The suggested methodology is evaluated by simulation with application to the complete nonlinear model of the biofilter. Copyright $\odot 2002$ IFAC
\end{abstract}

Keywords: Model-based control, Adaptive control, Least-squares estimation, Biotechnology, Distributed-parameter systems.

\section{INTRODUCTION}

This paper is concerned with the generalised approach to the design of the adaptive controller, which is to be applied to regulate the total nitrates and nitrites concentrations at the outlet of the granular fixed bed biofilter (Bourrel, 1996; Jacob et al., 1996; Babary and Bourrel, 1999; Bourrel et al., 2000) with the velocity of the flowing medium as the control variable.

This work is a generalisation of the approach suggested in (Babary and Bourrel, 1999; Bourrel et al., 2000). Although in those works the lack of modelling accuracy (basically of the process kinetics) was considered, it was necessary to know the complete form of one subset of the mathematical model of the biofilter to manage the estimation problem. Strictly speaking, it had to be assumed that some of the model parameters (namely the yield coefficients and the death/detachment coefficients) were constant and known from the off-line identification experiments. Next, on the basis of the dynamic equation, describing the biomass evolution, a nonlinear observer for that value was proposed. That observer was then used for the on-line estimation of the specific growth rate and afterwards both those values were applied to provide the adaptability of the control law. The control law itself was derived on the basis of the dynamic equation describing the nitrate and nitrite concentrations, which was obtained by combining the part of the

\footnotetext{
* Author to whom all the correspondence should be addressed.
} 
complete mathematical model of the biofilter. Let us note that the main drawback of such an approach is that in some cases it cannot be used in the practice because there is not only a large uncertainty on the process kinetics but also on the form of the mathematical model. Moreover, in certain cases the multiparameter identification (the observer for the biomass concentration and the estimate for the specific growth rate) can give inaccurate results.

Our approach, suggested in this paper, is based on the application of the substrate consumption rate to the adaptive control of distributed parameter bioreactors (Czeczot et al., 1998; Babary et al., 1999; Czeczot et al., 2000). In our opinion this is the interesting alternative for the approach described above. We assume that the mathematical model of the biofilter is completely unknown. There can be a large uncertainty not only on the process kinetics, but also on the knowledge about biochemical reactions taking place. Moreover, even some components of reactions can be unknown. We only need to define the control goal and, consequently, the controlled and control variables. We also need a basic knowledge about the process dynamics and on the basis of this knowledge we derive the simplified partial differential equation describing the controlled variable. This equation has a simplified form because it is based on the common mass balance considerations with the only one time varying term, which represents all unknown rates of reactions influencing the controlled variable at the biofilter outlet. Such an equation is then modified and used both for the controller design and for the estimation of the unknown term. This estimation provides adaptability of our control law. It is worth noting that there is only one parameter to estimate and thus we avoid the common difficulties with the multivariable identification.

This paper is organised as follows. A mathematical model of the biofilter is given in Section 2. Section 3 is devoted to the design of the suggested controller. Simulation results that prove very good control performance of this controller are presented in Section 4. Concluding remarks complete the paper.

\section{MATHEMATICAL MODEL OF THE BIOFILTER}

The dynamic model of the biofilter (Jacob et al., 1996; Babary and Bourrel, 1999; Bourrel et al., 2000), deduced from the mass balance considerations, consists of four partial differential equations describing the following components concentrations: nitrate $\mathrm{S}_{\mathrm{NO} 3}\left[\mathrm{~g} \mathrm{~N} / \mathrm{m}^{3}\right]$, nitrite $\mathrm{S}_{\mathrm{NO} 2}$ [g N/m $\left.\mathrm{m}^{3}\right]$, carbon $\mathrm{S}_{\mathrm{C}}\left[\mathrm{g} \mathrm{COD} / \mathrm{m}^{3}\right]$ and active biomass $\mathrm{X}_{\mathrm{a}}\left[\mathrm{g} \mathrm{COD} / \mathrm{m}^{3}\right]$.

$$
\begin{gathered}
\frac{\partial \mathrm{S}_{\mathrm{NO} 3}(\mathrm{z}, \mathrm{t})}{\partial \mathrm{t}}=-\frac{\mathrm{w}}{\varepsilon \mathrm{L}} \frac{\partial \mathrm{S}_{\mathrm{NO} 3}(\mathrm{z}, \mathrm{t})}{\partial \mathrm{z}}- \\
-\frac{1-\mathrm{Y}_{\mathrm{h} 1}}{1.14 \mathrm{Y}_{\mathrm{h} 1} \varepsilon} \mu_{\mathrm{NO} 3} \mathrm{X}_{\mathrm{a}}(\mathrm{z}, \mathrm{t}) \\
\frac{\partial \mathrm{S}_{\mathrm{NO} 2}(\mathrm{z}, \mathrm{t})}{\partial \mathrm{t}}=-\frac{\mathrm{w}}{\varepsilon \mathrm{L}} \frac{\partial \mathrm{S}_{\mathrm{NO} 2}(\mathrm{z}, \mathrm{t})}{\partial \mathrm{z}}+ \\
+\frac{1-\mathrm{Y}_{\mathrm{h} 1}}{1.14 \mathrm{Y}_{\mathrm{h} 1} \varepsilon} \mu_{\mathrm{NO} 3} \mathrm{X}_{\mathrm{a}}(\mathrm{z}, \mathrm{t})- \\
-\frac{1-\mathrm{Y}_{\mathrm{h} 2}}{1.71 \mathrm{Y}_{\mathrm{h} 2} \varepsilon} \mu_{\mathrm{NO} 2} \mathrm{X}_{\mathrm{a}}(\mathrm{z}, \mathrm{t}) \\
\frac{\partial \mathrm{S}_{\mathrm{C}}(\mathrm{z}, \mathrm{t})}{\partial \mathrm{t}}=-\frac{\mathrm{w}}{\varepsilon \mathrm{L}} \frac{\partial \mathrm{S}_{\mathrm{C}}(\mathrm{z}, \mathrm{t})}{\partial \mathrm{z}}- \\
-\frac{1}{\mathrm{Y}_{\mathrm{h} 1} \varepsilon} \mu_{\mathrm{NO} 3} \mathrm{X}_{\mathrm{a}}(\mathrm{z}, \mathrm{t})- \\
-\frac{1}{\mathrm{Y}_{\mathrm{h} 2} \varepsilon} \mu_{\mathrm{NO} 2} \mathrm{X}_{\mathrm{a}}(\mathrm{z}, \mathrm{t}) \\
\frac{\partial \mathrm{X} \mathrm{a}(\mathrm{z}, \mathrm{t})}{\partial \mathrm{t}}=\left(\mu_{\mathrm{NO} 3}+\mu_{\mathrm{NO} 2}\right)\left(1-\frac{\mathrm{X}_{\mathrm{a}}(\mathrm{z}, \mathrm{t})}{\mathrm{X}_{\mathrm{a} m a x}}\right) \mathrm{X}_{\mathrm{a}}(\mathrm{z}, \mathrm{t})
\end{gathered}
$$

In the above model the boundary conditions $\mathrm{S}_{\mathrm{NO} 3}(0, \mathrm{t})=\mathrm{S}_{\mathrm{NO} 3, \text { in }}(\mathrm{t}), \quad \mathrm{S}_{\mathrm{NO} 2}(0, \mathrm{t})=\mathrm{S}_{\mathrm{NO} 2, \mathrm{in}}(\mathrm{t})$, $\mathrm{S}_{\mathrm{C}}(0, \mathrm{t})=\mathrm{S}_{\mathrm{C}, \text { in }}(\mathrm{t})$ and the initial profiles $\mathrm{S}_{\mathrm{NO} 3}(\mathrm{z}, 0)$, $\mathrm{S}_{\mathrm{NO} 2}(\mathrm{z}, 0), \mathrm{S}_{\mathrm{C}}(\mathrm{z}, 0), \mathrm{X}_{\mathrm{a}}(\mathrm{z}, 0)$ are given.

In the equations (1a-1d) $\mathrm{z} \in[0,1]$ is the dimensionless space variable, $\varepsilon$ denotes the porosity, $\mathrm{Y}_{\mathrm{h} 1}$ and $\mathrm{Y}_{\mathrm{h} 2}-$ the yield coefficients [ - ] of the denitratation and denitritation reactions, respectively, $\mathrm{w}-$ the superficial velocity $[\mathrm{m} / \mathrm{h}], \mathrm{L}-$ the length of the biofilter, $X_{a} \max -$ the maximal active biomass concentration $\left[\mathrm{g} \mathrm{COD} / \mathrm{m}^{3}\right]$. The specific growth rates of the denitratation $\left(\mu_{\mathrm{NO} 3}[1 / \mathrm{h}]\right)$ and of the denitritation $\left(\mu_{\mathrm{NO} 2}[1 / \mathrm{h}]\right)$ reactions are typically described with a double Monod-type model (Monod, 1949; Bastin and Dochain, 1990):

$$
\begin{aligned}
& \mu_{\mathrm{NO} 3}=\mu_{\mathrm{NO} 3 \max } \frac{\mathrm{S}_{\mathrm{NO} 3}}{\mathrm{~S}_{\mathrm{NO} 3}+\mathrm{K}_{\mathrm{NO} 3}} \frac{\mathrm{S}_{\mathrm{C}}}{\mathrm{S}_{\mathrm{C}}+\mathrm{K}_{\mathrm{C}}} \\
& \mu_{\mathrm{NO} 2}=\mu_{\mathrm{NO} 2 \max } \frac{\mathrm{S}_{\mathrm{NO} 2}}{\mathrm{~S}_{\mathrm{NO} 2}+\mathrm{K}_{\mathrm{NO} 2}} \frac{\mathrm{S}_{\mathrm{C}}}{\mathrm{S}_{\mathrm{C}}+\mathrm{K}_{\mathrm{C}}}
\end{aligned}
$$

where $\mu_{\mathrm{NO} 3 \max }[1 / \mathrm{h}]$ and $\mu_{\mathrm{NO} 3 \max }[1 / \mathrm{h}]$ are the maximum values of the corresponding specific growth rates. $\mathrm{K}_{\mathrm{NO} 3}\left[\mathrm{~g} \mathrm{~N} / \mathrm{m}^{3}\right], \mathrm{K}_{\mathrm{NO} 2}\left[\mathrm{~g} \mathrm{~N} / \mathrm{m}^{3}\right]$ and $\mathrm{K}_{\mathrm{C}}$ [g COD $/ \mathrm{m}^{3}$ ] are the affinity constants associated to nitrate, nitrite and carbon, respectively. 


\section{CONTROLLER DESIGN}

In the case of the considered biofilter (1) the control goal is to regulate the total concentration of nitrates and nitrites

$$
\mathrm{y}_{\text {out }}(\mathrm{t})=\mathrm{y}(1, \mathrm{t})=\mathrm{S}_{\mathrm{NO} 3 \text {, out }}(\mathrm{t})+\mathrm{S}_{\mathrm{NO} 2 \text {,out }}(\mathrm{t})
$$

at the biofilter outlet at some desired value $\mathrm{y}_{\mathrm{d}}$ by manipulating the velocity of the flowing medium $w(t)$.

As it was said in Section 1, in most of practical cases the complete mathematical model of the biofilter (1) is not given, and even if it is given, there is still a large uncertainty associated to the process kinetics as well as to the model parameters. Thus, under these restrictions, the only way is to suggest the controller design on the basis of the general and simplified partial differential equation describing the controlled quantity $\mathrm{y}(\mathrm{z}, \mathrm{t})$ (Czeczot, 1995; Babary et al., 1999; Metzger, 2000):

$$
\frac{\partial \mathrm{y}(\mathrm{z}, \mathrm{t})}{\partial \mathrm{t}}=-\frac{\mathrm{w}(\mathrm{t})}{\mathrm{L}} \frac{\partial \mathrm{y}(\mathrm{z}, \mathrm{t})}{\partial \mathrm{z}}-\mathrm{r}_{\mathrm{y}}(\mathrm{z}, \mathrm{t})
$$

where $r_{y}(z, t)$ is the time varying term that represents the kinetics of the denitratation and the denitritation reactions, which influence the total concentration of nitrates and nitrites $\mathrm{y}(\mathrm{z}, \mathrm{t})$.

The equation (3) describes the dynamics of $y(z, t)$ at each internal point along the biofilter and thus on its basis the dynamic equation can be written for our controlled variable:

$$
\frac{\mathrm{dy}_{\text {out }}(\mathrm{t})}{\mathrm{dt}}=-\left.\frac{\mathrm{w}(\mathrm{t})}{\mathrm{L}} \frac{\partial \mathrm{y}(\mathrm{z}, \mathrm{t})}{\partial \mathrm{z}}\right|_{\mathrm{z}=1}-\mathrm{r}_{\mathrm{y}, \text { out }}(\mathrm{t})
$$

with $r_{y, \text { out }}(t)=r_{y}(1, t)$.

Now we can design the linearising controller on the basis of the simplified equation (4). If we wish to have the following stable first-order closed loop dynamics (Isidori, 1989; Bastin and Dochain, 1990):

$$
\frac{\mathrm{dy}_{\text {out }}(\mathrm{t})}{\mathrm{dt}}=\lambda\left(\mathrm{y}_{\mathrm{d}}-\mathrm{y}_{\text {out }}(\mathrm{t})\right), \quad \lambda>0,
$$

we can combine the equations (4) and (5) and in result we obtain the following expression for our linearising controller:

$$
w(t)=L \frac{-\lambda\left(y_{d}-y_{\text {out }}(t)\right)-r_{y, \text { out }}(t)}{\left.\frac{\partial y(z, t)}{\partial z}\right|_{z=1}}
$$

If we want to use the controller (6) in practice, we must manage two following difficulties:

- The value of the term $r_{y, o u t}(t)$ is unknown and unmeasurable on-line. Moreover, there is a large uncertainty on the possible expression describing its value. Therefore there is a need to apply the estimation procedure to obtain the value of this term. This procedure is based on the equation (4) with the application of the recursive least-squares method with the adjustable forgetting factor $\alpha_{\mathrm{f}}$ (Czeczot, 1997; Czeczot et al., 1998; Czeczot et al., 2000). It allows us to estimate the value of the term $r_{y, \text { out }}(t)$ as of the only one time varying parameter and thus we avoid the common difficulties with the multivariable identification. The estimation procedure is carried out on-line and in result we obtain the estimate of the unknown value of $r_{y, \text { out }}(t)$ at discrete moments of time.

- At the denominator of the control law (6) there is the space derivative of the controlled variable at the biofilter outlet. The same space derivative must be known for the estimation procedure described above. This value is unknown in practical cases but it can be approximated on-line by the orthogonal collocation method (Villadsen and Michelsen, 1978; Tali-Maamar, 1994). We only need the measurement data from the sensors of the concentrations of nitrate and of nitrite at the input and at the output as well as at some internal points along the biofilter. These points are the internal collocation points and such an approach allows us to combine high approximation accuracy with the possibly small number of the sensors being in use.

Considering the above we can suggest the final form of the nonlinear adaptive controller:

$$
\mathrm{w}^{\mathrm{i}}=\mathrm{L} \frac{-\lambda\left(\mathrm{y}_{\mathrm{d}}-\mathrm{y}_{\text {out }}^{\mathrm{i}}\right)-\hat{\mathrm{r}}_{\mathrm{y}, \text { out }}^{\mathrm{i}}}{\mathrm{A}_{\mathrm{z}=1}^{\mathrm{i}}}
$$

where $\mathrm{i}$ denotes the discretisation instant, $\hat{\mathrm{r}}_{\mathrm{y}, \text { out }}^{\mathrm{i}}$ is the estimate of the value of $r_{y, \text { out }}(t)$ and $A_{z=1}^{i}$ represents the approximation of the unknown value of the space derivative that exists at the denominator of the expression (6). The control law (7) has a discretetime form because it is assumed that the measurement data of the concentrations of nitrate and of nitrite is accessible only at discrete moments of time and, in result, the estimate $\hat{\mathrm{r}}_{\mathrm{y}, \text { out }}^{\mathrm{i}}$ is also calculated at the same discrete moments of time. The adaptability of the suggested controller (7) consists of considering the estimate $\hat{r}_{\mathrm{y}, \text { out }}^{\mathrm{i}}$ instead of the unknown value of $r_{y, \text { out }}(t)$. In the controller (7) $\lambda$ is the only one tuning parameter. 
It is worth noting that the simplification in the form of the equation (3) lays not only in the application of the one time varying parameter $r_{y, \text { out }}(z, t)$ but also in the fact that the porosity parameter $\varepsilon$ is not considered at all. It is in line with the assumption that the value of $\varepsilon$ is unknown. In consequence, this value is not included in the estimation procedure and in the final control law (7). In the next Section it is shown that although this fact significantly influences the estimation accuracy, it is not important for the control performance of the controller (7).

\section{SIMULATION RESULTS}

In this Section the selected simulation results of the control performance of the suggested adaptive controller (7) are presented. For the simulation experiments the complete mathematical model of the biofilter (1) is approximated by a set of ordinary differential equations with application of the orthogonal collocation method (Villadsen and Michelsen, 1978). The optimal choice of the number of the collocation points $\mathrm{N}=5$ and of the parameters determining the internal points location $\alpha=1$ and $\beta=1$ (Bourrel, 1996). Simulation runs have been carried out with the following parameters of the model (1) (Bourrel et al., 2000): $\mathrm{Y}_{\mathrm{h} 1}=0.51, \quad \mathrm{Y}_{\mathrm{h} 2}$ $=0.42, \mu_{\mathrm{NO} 3 \max }=0.35, \mu_{\mathrm{NO} 2 \max }=0.27, \quad \mathrm{~K}_{\mathrm{NO} 3}=$ $1.5, \mathrm{~K}_{\mathrm{NO} 2}=1, \mathrm{~K}_{\mathrm{C}}=40, \varepsilon=0.52, \mathrm{~L}=1$ and $\mathrm{X}_{\mathrm{a} \max }=675$. In the steady state $\mathrm{S}_{\mathrm{NO} 3 \text {,in }}=16.93$, $\mathrm{S}_{\mathrm{NO}, \text { in }}=0, \mathrm{~S}_{\mathrm{C}, \text { in }}=101.5, \mathrm{w}=6$. For the estimation procedure the forgetting factor $\alpha_{\mathrm{f}}=0.1$ and the initial value of $\hat{r}_{\mathrm{y}, \text { out }}^{0}=77.0$ The sampling time for both the controller (7) and the estimation procedure $\mathrm{T}_{\mathrm{R}}=18$ [min]. The tuning parameter $\lambda=1$.

The control performance of the suggested controller (7) and the estimation accuracy in the closed loop are presented in this Section. During the first twenty hours the biofilter is operated in open loop. After this time the control law is applied first to adjust the output $\mathrm{y}_{\text {out }}(\mathrm{t})$ at its desired value $\mathrm{y}_{\mathrm{d}}=5.65$ and then to decrease the influence of the indicated step changes of the disturbing parameters.

Fig. 1 shows a very good control performance of the control law in the presence of the desired value and parameter changes. In spite of these disturbances the desired value $y_{d}$ is always reached and tracked. The control value varies smoothly and slowly, which is very important in the practical applications.

The estimation accuracy during the same closed-loop experiment is shown in the Fig. 2. Note that although the plot of the estimate $\hat{r}_{\mathrm{y}, \text { out }}^{\mathrm{i}}$ has a very similar shape to its true value $r_{y, \text { out }}(t)$, there is a large and constant bias between these two values. This bias is due to the fact that in the simplified equation (3) and, in consequence, in the estimation procedure that is based on this equation, the porosity parameter $\varepsilon$ is not considered. However, the influence of this modelling inaccuracy is compensated in the control law (7) by this difference between the true value of $r_{y, \text { out }}(t)$ and its estimate $\hat{r}_{y, \text { out }}^{\mathrm{i}}$. In consequence this inaccuracy has no influence on the control performance of the suggested adaptive controller (7). This property is very important and it ensures the possibility of the application of this approach to a wider class of processes in which the porosity influence is not known. Let us note that when the value of $\varepsilon$ is known it can be easily included in the form of the equation (3) to improve the estimation accuracy but without any influence on the control performance.

\section{CONCLUDING REMARKS}

In this paper the generalised approach to the adaptive control of the denitrifying biofilter with application of the substrate consumption rate is studied. It is shown how to derive the control law without any knowledge not only about the process kinetics but also about the complete form of the full nonlinear mathematical model of the process. This control law has been evaluated by simulation with application to the complete nonlinear mathematical model of the biofilter given in Section 2. Simulation results prove very a good control performance of the suggested controller in the presence of the desired value and of the disturbing parameters changes.

It must be said that the methodology presented in this paper is very useful for the control of the biofilter but not for its monitoring. The control law is derived assuming the possibly minimal knowledge about the process and this property makes this methodology very general. However, in the case when monitoring is needed, the more precise mathematical description of the biofilter must be used and some knowledge about the process kinetics must be assumed to derive necessary observers and to apply the off-line and online identification techniques. Let us note that the idea of the substrate consumption rate can be also suggested for the monitoring of such processes (Czeczot, 1995, 1997; Czeczot et al., 2001) but in this particular case the porosity parameter must be known and considered.

For the approach presented in this paper, it is assumed that the nitrate and nitrite concentrations are measured not only at the input and at the output but also at some internal points along the biofilter (in this case at the collocation points). Of course such an assumption ensures a better control performance but it must be said that in practice, usually it is very difficult to obtain measurement data at internal 
points. In this case we can use the approximation of the space derivative of the controlled variable based on the finite difference method (Bourrel et al., 2000) or to apply similar but more general methodology called Balance-Based Adaptive Control (Czeczot, 2001).

To summarise, let us note that the presented methodology can be suggested for practical application. It is very general since both the adaptive controller and the estimation procedure are based on the simplified form of the dynamical equation written for the controlled variable. The very important properties of this methodology are its very good control performance and its simplicity, which allows it to be easily implemented even on the simple PLC devices.

Acknowledgements: This work was supported by Polish Committee of Scientific Research (KBN) and by the French Ministry of Foreign Affairs under grant POLONIUM no. 99062.
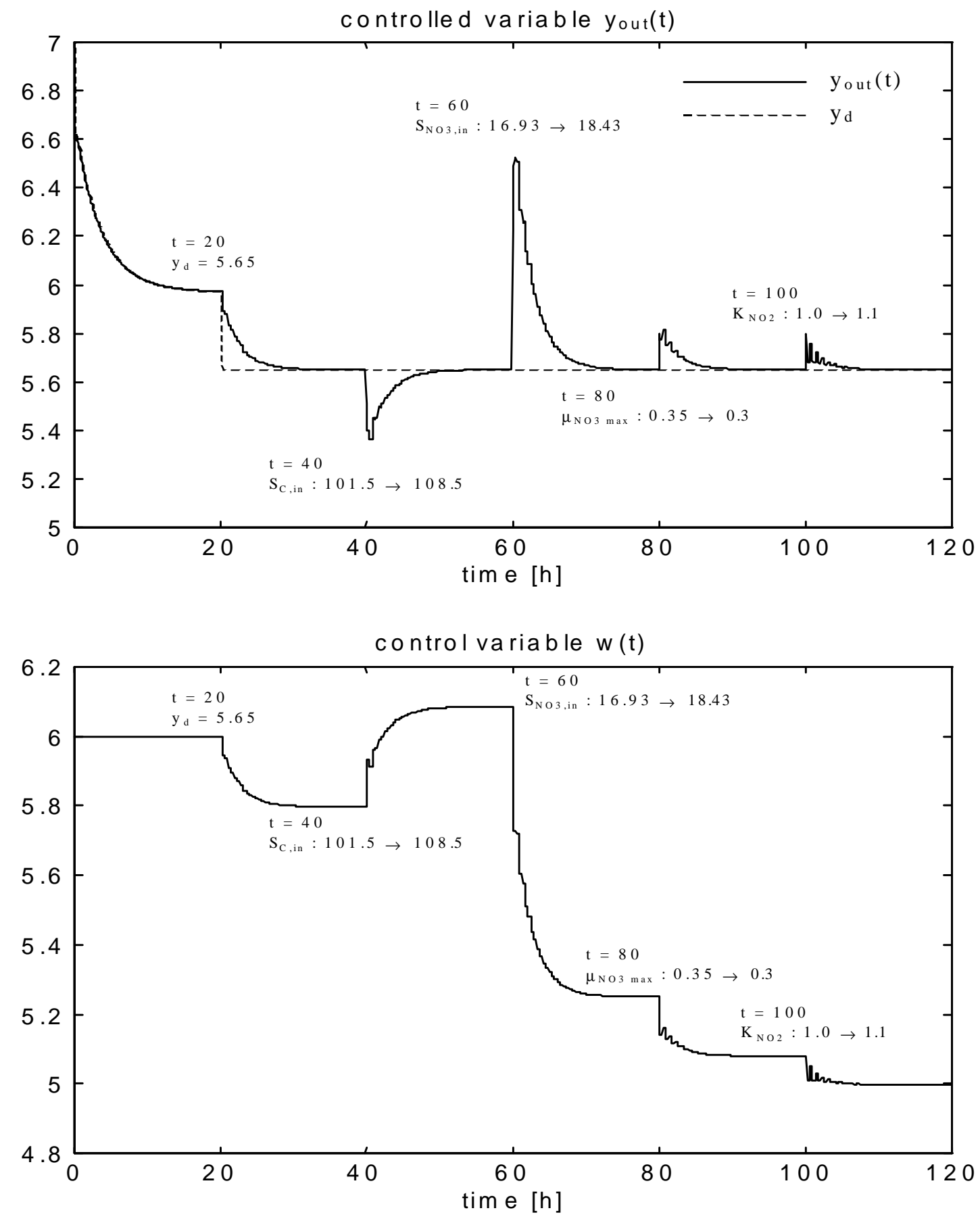

Fig.1. Adaptive control of the biofilter 


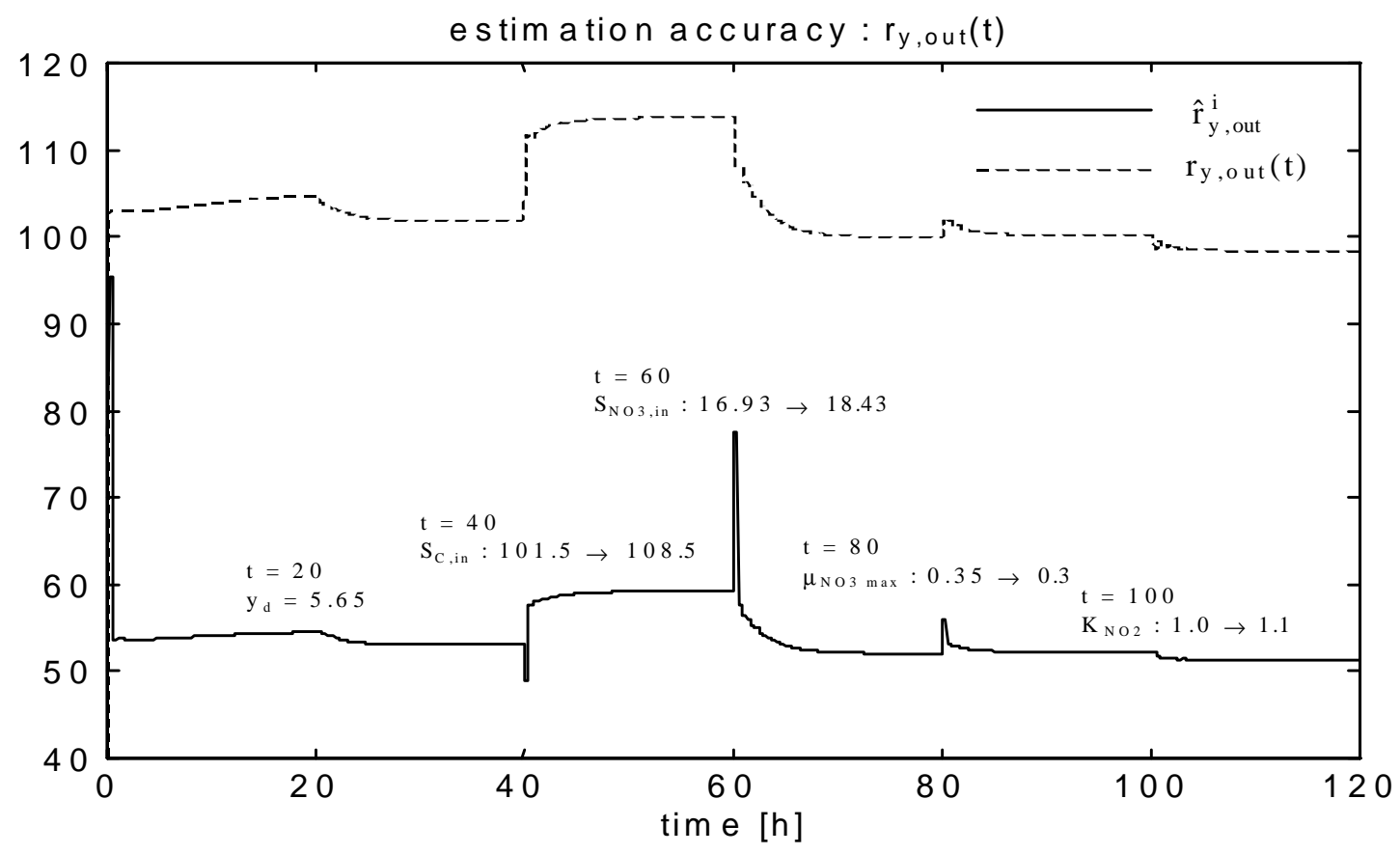

Fig. 2. Estimation accuracy in closed loop

\section{REFERENCES}

Babary J.P., Bourrel S. (1999). Sliding mode control of a denitrifying biofilter. Applied Mathematical Modelling, 23, pp. $609-620$.

Babary J.P., Julien S., Nihtilä M.T., Czeczot J., Metzger M. (1999). New boundary conditions and adaptive control of fixed-bed bioreactors. Chem. Engng. and Processing, 38, pp. 35-44.

Bastin G., Dochain D. (1990). On-line estimation and adaptive control of bioreactors. Elsevier Science Publishers B.V..

Bourrel S. (1996). Estimation et commande d'un procédé à paramètres répartis utilisé pour le traitement biologique de l'eau à potabiliser. Doctoral dissertation, Université Paul Sabatier, Toulouse, France.

Bourrel S., Dochain D., Babary J.P., Queinnec I. (2000). Modelling, identification and control of a denitrifying biofilter. Journal of Process Control, 10, No. 1, pp. 73 - 91 .

Czeczot J. (1995). Substrate consumption rate - New concept of measuring and monitoring in the activated sludge process. Proc. of the IFAC International Conference on Computer applications in Biotechnology, Pergamon Elsevier, pp. 205-208.

Czeczot J. (1997). The application of the substrate consumption rate to the monitoring and control of the biological processes of water purification. $\mathrm{Ph}$. D. Thesis, Technical University of Silesia, Gliwice, Poland (in polish).

Czeczot J. (2001). New approach to the adaptive control of a class of distributed parameter bioreactors. MMAR 2001, 28 - 31 August 2001, Miedzyzdroje, Poland (accepted).
Czeczot, J., Babary, J.P., and Nihtilä, M.T. (1998). Adaptive control of a distributed parameter bioreactor based on the substrate consumption rate estimation. International Workshop on Decision and Control on Waste Bioprocessing, Narbonne, France.

Czeczot J., Metzger M., Babary J.P., Nihtilä M. (2000). Filtering in adaptive control of distributed parameter bioreactors in the presence of noisy measurements. Simulation Practice and Theory, 8, No. 1-2, pp. 39-56.

Czeczot J., Metzger M., Babary J.P., Nihtilä M. (2001). Application of the substrate consumption rate to the monitoring of distributed parameter bioreactors. Control and Cybernetics, 30, No. 1.

Isidori A. (1989). Non-linear control systems. Springer, Berlin.

Jacob J., Pingaud. H, Le Lann J.M., Bourrel S., Babary J.P., Capdeville B. (1996). Dynamic simulation of biofilters. Simulation Practice and Theory, 4, pp. $335-348$.

Metzger M. (2000). Modelling, simulation and control of continuous processes. Edition of Jacek Skalmierski Computer Studio. Gliwice. Poland.

Monod J. (1949). The growth of bacterial cultures. Ann. Rev. Microbial, 3, pp. 371-394.

Tali-Maamar N. (1994). Modélisation, analyse et commande d'un procédé biotechnologique a gradient spatial de concentration. Doctoral dissertation, Université Paul Sabatier, Toulouse, France.

Villadsen J.V., Michelsen M.L. (1978). Solution of differential equation models by polynomial approximation. Prentice Hall, Englewood Cliffs, NJ. 